\title{
Vitamin $C$ intake and susceptibility to the common cold
}

\author{
BY HARRI HEMILÄ \\ Department of Public Health, POB 41, University of Helsinki, FIN-00014 Finland
}

(Received 6 December 1995 - Revised 7 May 1996 - Accepted 15 May 1996)

\begin{abstract}
Although the role of vitamin $C$ in common cold incidence had been studied extensively, the level of vitamin $C$ intake has not been unequivocally shown to affect the incidence of colds. In the present study the six largest vitamin $C$ supplementation ( $\geq 1 \mathrm{~g} / \mathrm{d}$ ) studies, including over 5000 episodes in all, have been analysed, and it is shown that common cold incidence is not reduced in the vitamin $C$ supplemented groups compared with the placebo groups (pooled rate ratio (RR) 0.99; $95 \%$ CI 0.93, 1.04). Consequently these six major studies give no evidence that high-dose vitamin $C$ supplementation decreases common cold incidence in ordinary people. Nevertheless, the analysis was continued with the hypothesis that vitamin $C$ intake may affect common cold susceptibility in specific groups of people. It was assumed that the potential effect of supplementation might be most conspicuous in subjects with low dietary vitamin $C$ intake. The average vitamin $C$ intake has been rather low in the $U K$ and plasma vitamin $C$ concentrations are in general lower in males than in females. In four studies with British females vitamin $\mathrm{C}$ supplementation had no marked effect on common cold incidence (pooled RR 0.95; $95 \%$ CI 0.86, 1.04). However, in four studies with British male schoolchildren and students a statistically highly significant reduction in common cold incidence was found in groups supplemented with vitamin $C$ (pooled RR 0.70; $95 \%$ CI 0.60, 0.81). Thus, these studies with British males indicate that vitamin $C$ intake has physiological effects on susceptibility to common cold infections, although the effect seems quantitatively meaningful only in limited groups of people and is not very large.
\end{abstract}

Ascorbic acid: Upper respiratory-tract infection: Common cold: Controlled trials

Phagocytes and lymphocytes concentrate vitamin $\mathrm{C}$ at levels up to 100 times higher than in plasma (Evans et al. 1982; Bergsten et al. 1990; Washko et al. 1993) suggesting that this vitamin has a physiological role in these immune-system cells. Vitamin $\mathrm{C}$ has been reported to increase the proliferative responses of T-lymphocytes in vitro (Manzella \& Roberts, 1979; Oh \& Nakano, 1988; Smit \& Anderson, 1990) and in some studies with human subjects (Yonemoto, 1979; Anderson et al. 1980; Kennes et al. 1983). Furthermore, vitamin $\mathrm{C}$ has been reported to increase the induced production of interferon in cell culture (Schwerdt \& Schwerdt, 1975; Siegel, 1975; Dahl \& Degre, 1976) and in mice (Siegel, 1974; Geber et al. 1975). Thus there are experimental studies indicating that vitamin C may have effects on the immune system. However, it is not known to what extent these reported effects have physiological relevance, for example, whether vitamin $\mathrm{C}$ intake in particular circumstances affects the susceptibility of human beings to infections.

The effects of vitamin C supplementation on the incidence of common cold episodes have been extensively studied. Placebo-controlled studies have consistently shown that high doses of the vitamin alleviate the symptoms of the common cold (Hemilä, 1992, 1994, 1996a; Hemilä \& Herman, 1995). In contrast, the results of vitamin C supplementation on the incidence of colds have been ambiguous. Although in a meta-analysis of four placebocontrolled studies Pauling (1971) found strong evidence that vitamin $\mathrm{C}$ supplementation decreases common cold incidence $(P<0.002)$, later studies have mostly found no 
substantial effect (Hemilä, 1992, 1994). Nevertheless, a significant reduction in the number of colds in the vitamin C-supplemented groups has been observed in some studies, suggesting that the issue deserves a detailed analysis. If vitamin $\mathrm{C}$ has physiologically important effects on the immune system, it is possible that these effects are quantitatively meaningful only in limited groups of people. It has been suggested that subjects under heavy acute physical stress is one of the groups in which vitamin $\mathrm{C}$ supplementation may decrease the incidence of the common cold (Hemilä, 1996b). Also, subjects with low dietary intake may form one of the groups in which the effects of supplementation are most apparent. The purpose of the present study was to see whether vitamin $\mathrm{C}$ supplementation has any consistent effect in subjects with a low dietary intake of the vitamin.

\section{METHODS}

\section{Selection of the studies}

The literature on vitamin C-common cold studies has been thoroughly surveyed by several authors (Briggs, 1984; Kleijnen et al. 1989; Hemilä, 1994), and two exhaustive reference lists have been published (Briggs, 1984; Kleijnen et al. 1989). The previous searches were extended by Medline and Scisearch database searches to identify vitamin C-common cold intervention studies published since 1988. Two groups of studies were selected for further analysis.

First, placebo-controlled double-blind studies in which $\geq 1 \mathrm{~g}$ vitamin $\mathrm{C} / \mathrm{d}$ was regularly administered and in which there were $\geq 200$ common cold episodes in all were sought. Seven studies belonging to this group were identified (Table 1). The second study by Anderson et al. (1974) is not included in Table 1, since there is evidence of bias in the distribution of subjects in the eight study groups (Anderson et al. 1974; Hemilä \& Herman, 1995). Nevertheless, the results of this latter study are not inconsistent with the results shown in Table 1. Anderson et al. (1972) corrected some parts of their data afterwards (Anderson et al. 1973). The results of the Karlowski et al. (1975) study were recently reanalysed (Hemilä, 1996a). In each of the six major studies included in Table 1 the subjects were randomly allocated to the study groups.

Second, studies carried out in the UK were searched for. Eight studies that had analysed the effect of vitamin $\mathrm{C}$ supplementation on common cold incidence were identified (Tables 2 and 3). Walker et al. (1967) examined the effect of vitamin C on experimental colds initiated by inoculation with common cold viruses. In experimental common cold infections a large dose of virus is used to infect as many subjects as possible during a short test period. However, if vitamin $\mathrm{C}$ has only quite modest physiological effects these may be detectable only when small doses of viruses challenge people in their normal daily lives, and not when very large infecting doses are used. Therefore Walker's study was not included in the analysis of the natural common cold infections (Tables 2 and 3). Carson et al. (1975) did not separate their subjects into men and women and so their study is not included in Table 2 or Table 3.

Glazebrook \& Thomson (1942) did not use a placebo but added the vitamin to the food of schoolboys, and the subjects were allocated to the study groups as seven divisions who occupied certain tables in the dining hall. All the other British studies were placebocontrolled. Four of the studies were double-blind and randomized (Carson et al. 1975; Elwood et al. 1976; Tyrrell et al. 1977; Baird et al. 1979). The method of allocation was not described by Charleston \& Clegg (1972) and Clegg \& Macdonald (1975); the latter study was double-blind but the former was not. The results of the Charleston \& Clegg (1972) study were originally published without division by sex, but in a later publication the data were separated for males and females (Clegg, 1974). 


\section{Statistical methods}

The one-tailed $P$ values are used in the text in discussing the difference between the vitamin $\mathrm{C}$ and control groups since there is no theoretical or experimental reason to expect that vitamin $\mathrm{C}$ supplementation could increase the incidence of the common cold, and because the explicit question in the present analysis was whether vitamin $\mathrm{C}$ supplementation decreases the incidence or not. When the published results have made it possible, the $P$ values have been recalculated using the $\chi^{2}$ test.

In Tables 1 and 2 the common cold incidence rate (I) in the study groups was calculated from the published results $\left(\mathrm{I}_{\mathrm{C}}\right.$ for the vitamin $\mathrm{C}$ group and $\mathrm{I}_{\mathrm{P}}$ for the placebo group). The number of person years and the incidence rate were calculated merely for the purpose of allowing comparison between the studies. The number of person years was not given in any study but was calculated from the duration of the study and the number of subjects, although in several cases the duration was not accurately described. Nevertheless, in Tables 1 and 2 the durations of the studies were equal for their respective vitamin $\mathrm{C}$ and placebo groups, allowing calculation of the rate ratio $R R\left(=I_{C} / I_{P}\right)$ directly from the numbers of subjects and episodes.

In Table 3 the outcome measure is dichotomous; the subjects are divided into two groups on the basis of either having or not having recurrent common cold infections during the study. The proportion of subjects falling sick during the study (p) was calculated from the published results $\left(\mathrm{p}_{\mathrm{C}}\right.$ for the vitamin $\mathrm{C}$ group and $\mathrm{p}_{\mathrm{P}}$ for the placebo group). In Table 3 the relative risk was calculated as the ratio of the proportions $\left(R R=p_{C} / p_{P}\right)$.

In certain studies the total number of episodes was not given, but rather the mean number of episodes per person. In these cases the total number of episodes was calculated as the product of the number of subjects and the mean number of episodes. Baird et al. (1979) gave the number of subjects who had had 0,1 or $\geq 2$ long colds (3-5d) and $0,1,2$ or $\geq 3$ short colds $(1-2 \mathrm{~d})$, but the total or average number of episodes was not given. The total number of episodes was calculated from the data on the approximation that $\geq 2$ and $\geq 3$ indicate 2 and 3 colds respectively, so that there are a few episodes missing.

The $95 \%$ confidence interval $(95 \% \mathrm{CI})$ for the $\mathrm{RR}$ found in each study was calculated with the normal distribution approximation of the Poisson distribution in Tables 1 and 2, and with the normal distribution approximation of the binomial distribution in Table 3 . With the normal distribution approximation the variances needed for the $95 \% \mathrm{CI}$ were calculated in Tables 1 and 2 as $\operatorname{var}(\log (R R))=\left(1 / E_{C}+1 / E_{P}\right)(E$ being the number of episodes), and in Table 3 as $\operatorname{var}(\log (R R))=\left[\left(1-p_{C}\right) / S_{C}+\left(1-p_{P}\right) / S_{P}\right](S$ being the number of subjects with $\geq 2$ episodes).

In Tables $1-3$ the pooled RR and the $95 \% \mathrm{CI}$ were derived by averaging the individual logarithm values $\log (R R)$ using the inverses of variances $\operatorname{var}(\log (R R))$ as the weights with the following formulas (Rothman, 1986):

$$
\begin{gathered}
\log \left(R_{R_{\text {Pool }}}\right)=\frac{\sum \log \left(R_{R_{i}}\right) / \operatorname{var}\left(\log \left(R_{R_{i}}\right)\right)}{\sum 1 / \operatorname{var}\left(\log \left(R_{R_{i}}\right)\right)}, \\
\operatorname{var}\left(\log \left(R_{R_{\text {Pool }}}\right)\right)=\frac{1}{\sum 1 / \operatorname{var}\left(\log \left(R_{R_{i}}\right)\right)},
\end{gathered}
$$

$95 \%$ CI limits: $\mathrm{RR}_{\mathrm{Up}, \text { Low }}=\mathrm{RR}_{\text {Pool }} \times \exp \left\{ \pm 1.96 \sqrt{\operatorname{var}\left(\log \left(\mathrm{RR}_{\text {Pool }}\right)\right)}\right\}$ 
In Table 2 Elwood et al.'s (1976) results are divided into 'simple' and 'chest' colds in order to visualize the possible difference between the two case definitions. Also, a single result from Elwood's study can be used in the pooling procedure (RR derived from the sum of the two subcategories), but this leads to identical pooled RR and $95 \% \mathrm{CI}$ values (results not shown). The one-tailed $P$ value corresponding to the pooled estimate (Tables 2 and 3 ) was derived from the standard normal deviate $\mathrm{z}=\log \left(\mathrm{RR}_{\text {Pool }}\right) / \sqrt{\operatorname{var}\left(\log \left(\mathrm{RR}_{\text {Pool }}\right)\right)}$.

\section{RESULTS}

\section{Pooling the results of six major studies with high vitamin $C$ doses}

If regular high-dose vitamin $C$ supplementation markedly decreases the incidence of the common cold as Pauling $(1970,1971)$ claimed, the most convincing evidence should be seen in studies in which a large dose of the vitamin is used and large numbers of common cold episodes are recorded. A study employing a low vitamin $\mathrm{C}$ dose could fail to show any effect simply because the dose was too small, and therefore $\geq 1 \mathrm{~g}$ vitamin $\mathrm{C} / \mathrm{d}$ was used as a criterion in selecting the major studies. As a second criterion it was required that at least 200 common cold episodes be observed in the study. Smaller studies were left out since small studies with negative results may remain unpublished, while there is much less risk of publication bias in the case of large-scale studies. Furthermore, the total number of episodes in the smaller studies with $\geq 1 \mathrm{~g}$ vitamin $\mathrm{C} / \mathrm{d}$ is approximately 1000 (Hemilä, 1992), so that even their combined weight is small compared with the weight of the six largest studies containing over 5000 common cold episodes in all (Table 1). None of these six major studies found a statistically significant decrease in common cold incidence. Furthermore, pooling the six studies did not reveal any meaningful overall difference between the vitamin and the placebo groups (Table 1). Thus the six major studies give no support to the suggestion that regular high-dose vitamin $\mathrm{C}$ supplementation markedly decreases the incidence of the common cold across a range of populations in Western countries.

Still, it is noteworthy that Anderson et al. (1972) found that $18 \%$ of the control group but $26 \%$ of the vitamin group remained free of illness during the study period $(P=0.006)$. Furthermore, if vitamin $C$ does have a small physiological effect it may depend on the type of infection; either on the aetiological agent or on the tissues affected. It is therefore noteworthy that Elwood et al. (1976) found a statistically significant decrease ( $-18 \%$; see Table 2) in the incidence of 'chest colds' (cough or other chest symptoms) in the vitamin C group, but no effect $(+1 \%)$ on the incidence of 'simple colds' (runny nose or sneezing). Similarly, Anderson et al. $(1972,1973)$ observed a moderate decrease in the incidence of 'throat colds' ( $-21 \% ; 0.34$ and 0.43 per subject), but no effect $(-2 \%)$ on the incidence of 'nose colds'. The latter authors did not comment on the possible statistical significance of the difference (Anderson et al. 1973), but assuming that there was at most one 'throat cold' episode per subject the difference is significant in the $\chi^{2}$ test $(P<0.01)$. In both of these two studies the number of 'nose colds' was about two-thirds of all colds. Accordingly, these two major studies suggest that vitamin $\mathrm{C}$ supplementation may have a slight effect on the incidence of certain types of common cold infections.

\section{Dietary vitamin $C$ intake in the six major studies}

If vitamin $C$ intake affects susceptibility to common cold infections, the effect of supplementation may be most pronounced in subjects with an initially low vitamin $\mathrm{C}$ intake. A large dietary intake probably causes saturation of any potential effects of vitamin 


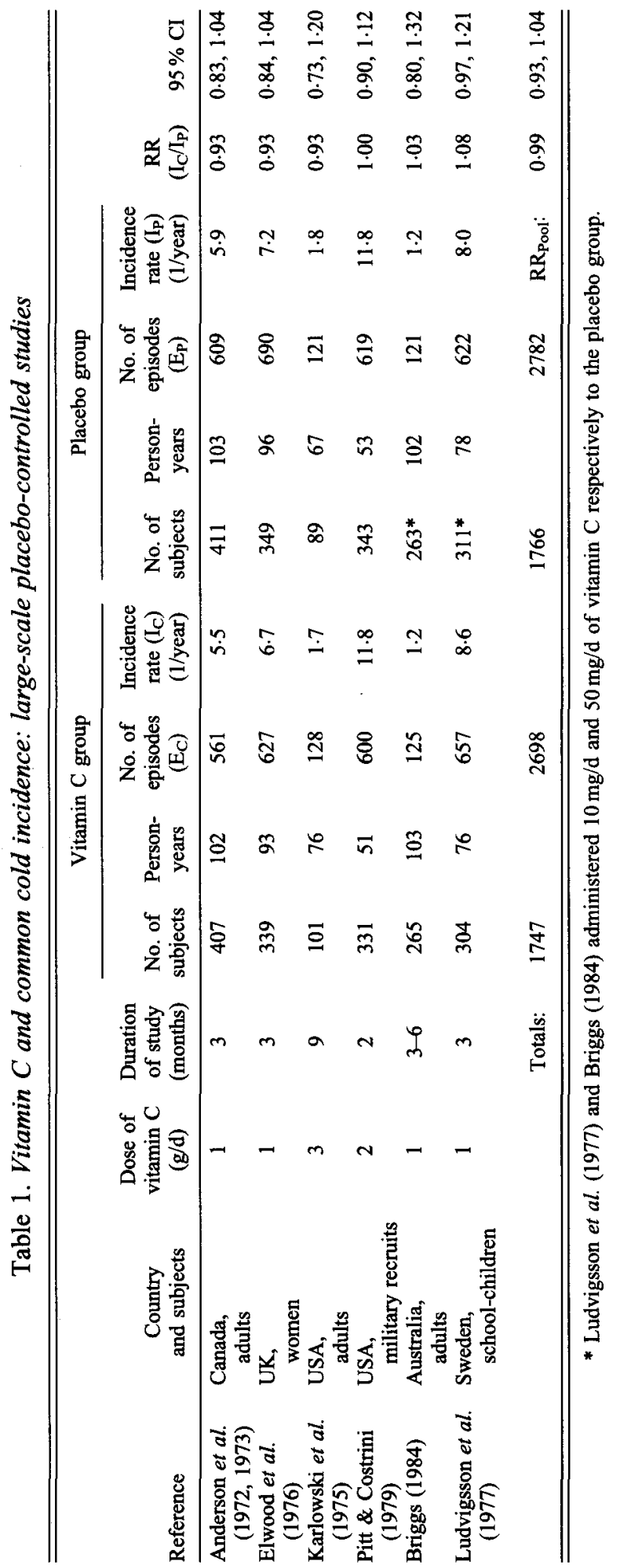


$\mathrm{C}$ on the immune system, whereas subjects with low levels of intake could suffer from some functional deficiencies in the immune system. In the latter case supplements could produce benefits from a correction of marginal deficiency, while in the former case supplements would produce no effect since the saturation levels have already been reached. Although the clinical signs of scurvy start to appear when plasma vitamin $C$ level decreases below $10 \mu \mathrm{mol} / 1$, there are large individual differences in the appearance of the symptoms (Hodges et al. 1971). If, then, marginal vitamin C deficiency increases susceptibility to common cold infections, the effect could be observed in studies in which vitamin $C$ intakes and plasma concentrations in the control subjects are rather close to the levels producing scurvy.

Regarding the role of dietary intake in the six major studies, Briggs (1984), Ludvigsson et al. (1977) and Pitt \& Costrini (1979) measured plasma vitamin C concentrations, fairly high mean levels being found in the control groups: 62,49 , and $52 \mu \mathrm{mol} / 1$ respectively. Only rather small increases in plasma vitamin $\mathrm{C}$ levels were found in the vitaminsupplemented groups compared with the placebo groups: $+18 \%,+24 \%$, and $+49 \%$ respectively. Furthermore, Briggs (1984) gave $50 \mathrm{mg}$ vitamin $\mathrm{C} / \mathrm{d}$ to the placebo subjects to avoid the possibility that any observed effect might result from the alleviation of a marginal deficiency. Consequently, these three studies are not critical as regards the question of whether low vitamin $C$ intake is associated with an increased susceptibility to common cold infections.

In the study by Karlowski et al. (1975), neither vitamin C intake nor plasma concentration was estimated. They used a sample of employees of the National Institutes of Health (Bethesda, MD, USA) as subjects, and it seems likely that such subjects have a much healthier diet (e.g. more fruits containing vitamin $\mathrm{C}$ ) than the population at large, so that this study may not be pertinent to the question of whether low vitamin $\mathrm{C}$ intake is associated with an increased number of cold episodes either.

Consistent with the possibility that dietary vitamin $\mathrm{C}$ intake modifies the effects of supplementation, Anderson et al. (1972) found that regular vitamin C supplementation $(1-4 \mathrm{~g} / \mathrm{d})$ decreased the total number of sickness days by $48 \%$ in subjects who drank less than 0.12 litres $(4 \mathrm{oz})$ of fruit juices daily, but only by $22 \%$ in subjects who drank more. The subgroup difference shows the importance of taking into account the initial dietary intake in considering the effects of supplementation. Fruit juices provide about half of all vitamin C intake (Block \& Sorenson, 1987), and thus the amount of juice provides a reasonable estimate of total vitamin $\mathrm{C}$ intake.

Thus, five of the major studies are not incompatible with the hypothesis that low vitamin $C$ intake may be associated with an increased susceptibility to common cold infections. The analysis was therefore continued on the hypothesis that many reported decreases in cold incidence with vitamin $\mathrm{C}$ supplementation are explainable by physiological effects which are, however, more properly interpreted as a correction of marginal deficiency than by the effects of high doses per se.

\section{Low level of dietary vitamin $C$ intake: the British studies}

Neither dietary vitamin $\mathrm{C}$ intake nor plasma vitamin $\mathrm{C}$ concentration has been examined in most of the common cold intervention studies and therefore a subgroup of studies cannot be selected with a well-defined criterion for poor initial vitamin status among the study subjects. A surrogate criterion was therefore used to select a strictly defined group of studies with subjects having relatively low vitamin $\mathrm{C}$ intake; namely studies carried out in the UK (Tables 2 and 3). 
Several studies over a long period have reported fairly low vitamin C intake in groups of subjects in the UK: $30-60 \mathrm{mg} / \mathrm{d}$ (Allen et al. 1968; Milne et al. 1971; Lonergan et al. 1975; Black et al. 1976; Smithells et al. 1977; Bates et al. 1979; Darke et al. 1980; Crombie et al. 1990; Bolton-Smith et al. 1993). By comparison, the mean vitamin C intake in the USA has been estimated to be $90-120 \mathrm{mg} / \mathrm{d}$ (Block \& Sorenson, 1987). Furthermore, in a recent comparison of middle-aged men in three European countries (Riemersma et al. 1990) the lowest plasma vitamin C concentrations were observed in the UK (median $18 \mu \mathrm{mol} / 1$ ), whereas the levels were twice as high in Italy (median $38 \mu \mathrm{mol} / \mathrm{l}$ ), and substantially higher in Finland as well (medians 28 and $33 \mu \mathrm{mol} / 1$ in two regions). Finally, the recommendation for vitamin C intake in the UK $(30 \mathrm{mg} / \mathrm{d}$ for adults) has been the lowest in Western Europe (Trichopoulou \& Vassilakou, 1990) being half of the recommended dietary allowance in the USA $(60 \mathrm{mg} / \mathrm{d}$; National Research Council, 1989). However, the UK recommendation was recently increased to $40 \mathrm{mg} / \mathrm{d}$ (Department of Health, 1991).

Dietary vitamin C intake was crudely estimated in two common cold studies carried out in the UK. Baird et al. (1979) estimated that their subjects received $50 \mathrm{mg}$ vitamin $\mathrm{C} / \mathrm{d}$ and Glazebrook \& Thomson (1942) estimated that their subjects received $10-15 \mathrm{mg} / \mathrm{d}$. Clegg \& Macdonald (1975) noted that the average British diet contains approximately $44 \mathrm{mg}$ vitamin $\mathrm{C} / \mathrm{d}$, although they did not estimate the intake of their own subjects. It is assumed in the present study that the dietary intake has also been low in the other common cold studies carried out in the UK although precise estimations have not been made by the authors of the reports.

\section{Pooling the results of the British studies}

So far seven British studies have examined the effect of vitamin $\mathrm{C}$ supplementation on the incidence of natural common cold infections. In Table 2 the results for males and females are separated. Usually plasma and leucocyte vitamin $C$ concentrations are lower in males than in females (Milne et al. 1971; Burr et al. 1974; Bates et al. 1979; Garry et al. 1982; Itoh et al. 1989; Oreopoulos et al. 1993), although it is not clear to what extent this is due to dietary and physiological differences between the sexes. Consequently a greater and more consistent effect on males should be expected from supplementation, assuming that low vitamin $\mathrm{C}$ levels increase susceptibility to colds. Four UK studies for which there are data for males found a lower incidence of colds in the vitamin C-supplemented group (Table 2). Pooling the four studies yields a combined rate ratio (RR) of 0.70 for common cold infections in the vitamin $\mathrm{C}$ groups. It is highly unlikely that the reported differences between the vitamin $\mathrm{C}$ and control groups in males were caused purely by chance.

The study by Glazebrook \& Thomson (1942) is the largest of the male studies in Table 2 and thus has great weight in the pooling procedure. However, there are numerous shortcomings in the study. For example, a placebo was not used, the vitamin being added to the food of the subjects, but much of the supplementary vitamin was degraded during the preparation of food. The study is also poorly described: for example, the duration of the study, the total number of episodes, and the exact amount of vitamin $\mathrm{C}$ added to food during the observation period are not described. If the Glazebrook \& Thomson (1942) study is excluded from the analysis because of the technical shortcomings, the RR estimate for males becomes $0.64(95 \%$ CI $0.53,0.77)$. Thus, the exclusion of the technically most deficient study leads to a somewhat increased difference between the pooled vitamin $\mathrm{C}$ and control groups.

The effect of vitamin $\mathrm{C}$ supplementation in females has been inconsistent, the pooled 


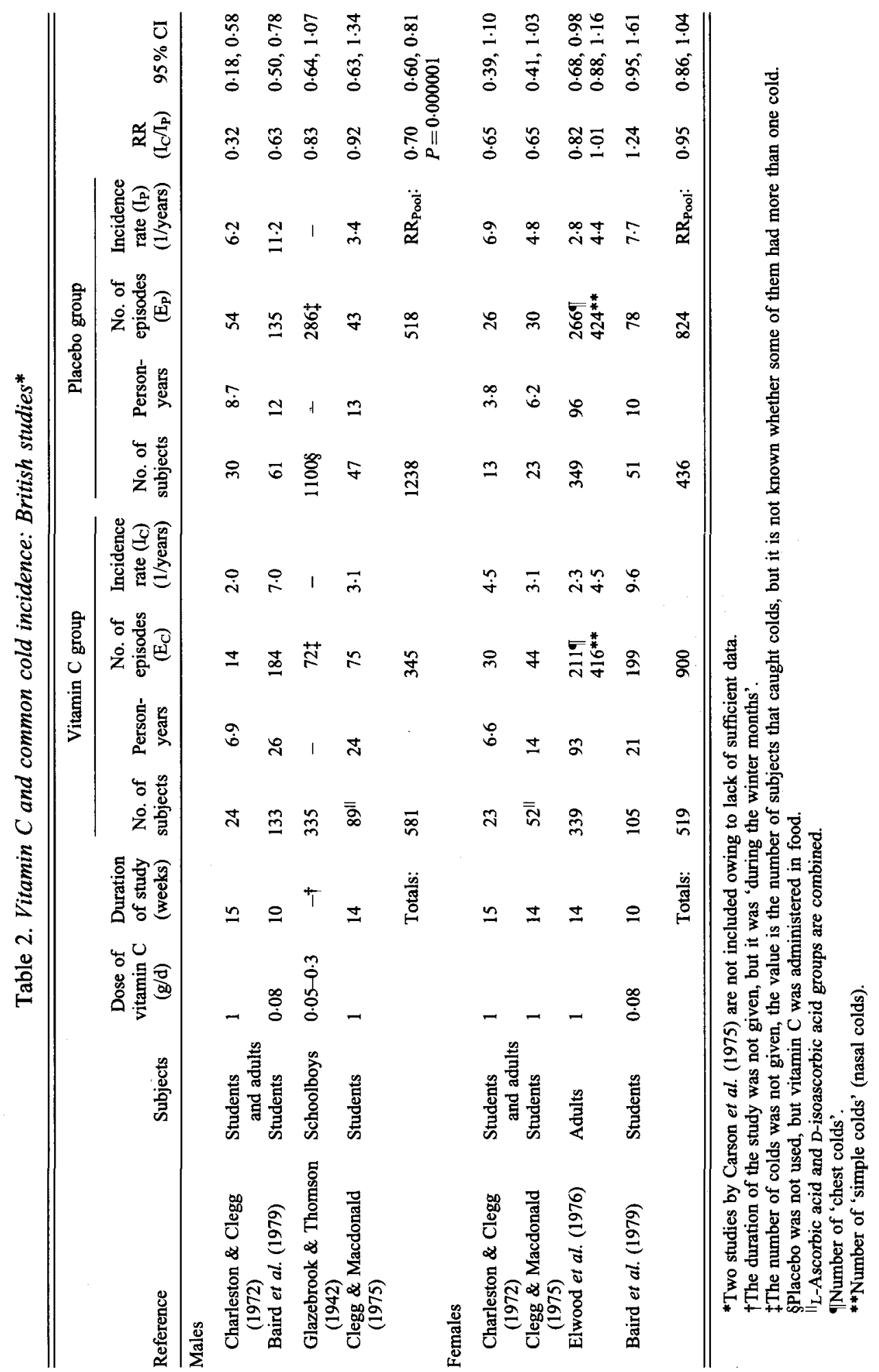




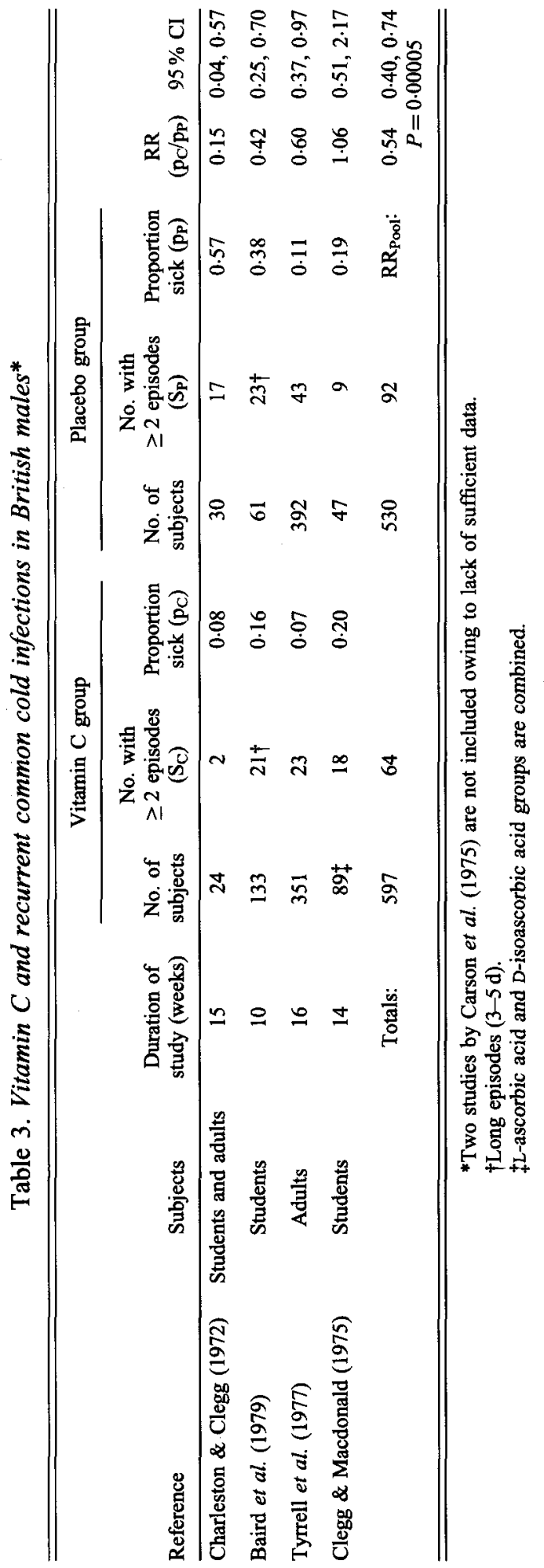


estimate suggesting that there is no marked overall effect (Table 2). Nevertheless, Elwood et al. (1976) found a statistically significant decrease in the incidence of 'chest colds'.

In addition to the studies in Table 2, Carson et al. (1975) carried out two 11-week studies in the UK on the effect of vitamin C $(1 \mathrm{~g} / \mathrm{d})$ on the incidence of colds with 244 adults of both sexes. No benefit was observed in either study. However, men and women were not separated in Carson's studies, preventing their inclusion in Table 2.

The British studies analysed in Table 2 used regular supplementation, i.e. vitamin C was administered each day during the study period. In contrast, Tyrrell et al. (1977) carried out a study in which they administered vitamin $C(4 \mathrm{~g} / \mathrm{d})$ for $2.5 \mathrm{~d}$ during the first cold episode only. They found a $40 \%$ decrease $(P=0.02)$ in the number of men with recurrent common cold infections. The effect of vitamin $\mathrm{C}$ on recurrent common cold infections in the studies with British males yielded a combined RR of 0.54 for subjects with recurrent infections in vitamin C-supplemented groups during the study period of 10-16 weeks (Table 3). In line with the small and inconsistent differences in females in the other studies (Table 2), Tyrrell et al. (1977) found no decrease in recurrent infections in women administered vitamin $\mathrm{C}$.

\section{DISCUSSION}

A large number of studies have been carried out to determine whether vitamin $\mathrm{C}$ supplementation decreases the incidence of common cold infections. In most studies the main incentive was to test Pauling's $(1970,1971)$ claim that large doses of vitamin C may prevent and alleviate colds. From the studies published so far it is clear that high-dose vitamin $\mathrm{C}$ supplementation has no marked effect on the number of common cold episodes in ordinary people (Table 1; Hemilä, 1992, 1994). Nevertheless, it is possible that vitamin C supplementation affects the susceptibility to colds in certain restricted groups of people. Subjects with low dietary intake of the vitamin would probably show the most conspicuous effects of supplementation assuming that the level of vitamin $\mathrm{C}$ intake is important.

The notion that a low level of vitamin $\mathrm{C}$ intake may increase susceptibility to infections is an old one (Robertson, 1934; Perla \& Marmorston, 1937a,b; Bourne, 1949). For example, early this century Höjer (1924) found that guinea pigs fed on a diet deficient in vitamin $\mathrm{C}$ readily contracted infections, mainly of the upper respiratory tract, but also pneumonia. Hess (1932) suggested that even in the absence of overt symptoms vitamin C deficiency lowers resistance to various infections.

Consequently, it is possible that in studies that have shown a reduction in common cold incidence in a study group supplemented with vitamin $\mathrm{C}$ the effect was not due to the high dosage per se, but rather to the correction of a marginal deficiency in the study subjects. This interpretation is not incompatible with the negative results of the six major studies (Table 1), which mostly used subjects with a fairly high dietary vitamin $\mathrm{C}$ intake. Nevertheless, two of the major studies suggested that vitamin $\mathrm{C}$ supplementation may have a slight effect on common cold incidence (Anderson et al. 1973; Elwood et al. 1976).

In the present paper the common cold studies carried out in the UK were selected for analysis, since low levels of vitamin $C$ intake have been observed in a number of UK studies indicating that average intake there has been fairly low. Pooling the results of four studies involving British males yielded strong evidence that vitamin $\mathrm{C}$ intake affects susceptibility to common cold infections (Table 2). A fifth UK study similarly found a statistically significant decrease in the incidence of recurrent colds in men supplemented with vitamin C (Table 3; Tyrrell et al. 1977). The studies by Baird et al. (1979) and Tyrrell et al. (1977) were randomized double-blind studies and therefore biases in the study groups 
do not provide simple explanations for the observed differences in these two studies in particular.

Pooling the studies involving British males yielded estimates of a $30 \%$ decrease in the number of common cold episodes (Table 2) and a $46 \%$ decrease in the number of males with recurrent infections (Table 3 ) with vitamin $\mathrm{C}$ supplementation. Nevertheless, these estimates should be interpreted as crude approximations. The primary purpose of the present study was to see whether vitamin C differs from placebo when common cold incidence is used as an outcome. If vitamin $\mathrm{C}$ intake does have an effect on the incidence there is obviously no single estimate for the effect size that is generally applicable. For example, with an increase in the dietary vitamin $\mathrm{C}$ intake the effect of supplementation evidently decreases towards nil, which may be the case in the studies in Table 1. It is also possible that there are other factors modifying the quantitative effects of vitamin $\mathrm{C}$ intake in a group of subjects. A considerable difference between the sexes was found in the UK studies (Table 2); also it is noteworthy that four studies of males showing a substantial effect with vitamin C supplementation used students and schoolchildren as subjects (Table 2). Carson et al. (1975) used adult men and women as subjects in two studies which showed no effect of supplementation, suggesting that the age of subjects could modify the role of vitamin C intake in susceptibility to the common cold. Tyrrell et al. (1977) also used adult men but still found a significant decrease in recurrent colds (Table 3). Neither of the latter two studies with adults described the mean age or the age range of their subjects, or other characteristics of the subjects, thereby hampering any more detailed comparisons. It appears likely that the characteristics of subjects and experimental conditions modify the role of vitamin $\mathrm{C}$ intake, but the limited data available do not allow any definite conclusions to be drawn. Thus, the studies with British males indicate that vitamin $\mathrm{C}$ intake has a physiological effect on the susceptibility to colds in certain people, but further studies are required for a more accurate estimate of the practical significance of this effect.

Baird et al. (1979) used only $80 \mathrm{mg}$ supplemental vitamin C/d and found a substantial decrease in common cold incidence in men. Baird et al. (1979) estimated that the dietary intake was $50 \mathrm{mg} / \mathrm{d}$ and, thus, the total intake in the vitamin C-supplemented group was approximately $130 \mathrm{mg} / \mathrm{d}$. Consequently this study gives the most direct support to the interpretation that it is the correction of marginal deficiency that is the reason for the observed benefit in the studies shown in Table 2.

Finally, the potential effect of vitamin C intake on susceptibility to the common cold also seems important as regards nutritional recommendations. It is noteworthy that in studies carried out in the UK a considerable decrease in common cold infections with vitamin C supplementation was found, while the recommended level of vitamin C intake in the UK has been the lowest in Western Europe (Trichopoulou \& Vassilakou, 1990). The goal of the nutritional recommendations is to prevent overt scurvy in healthy people and for that purpose $10 \mathrm{mg}$ vitamin C/d is sufficient (National Research Council, 1989; Department of Health, 1991). Nevertheless, the nutritional recommendations of $30-60 \mathrm{mg} / \mathrm{d}$ are not based either on epidemiological studies or on clinical trials, suggesting that such doses are better than $10 \mathrm{mg} / \mathrm{d}$ as regards any health status outcome. The purpose is merely to provide passive 'reserves' against scurvy (Hemilä, 1984, 1986, 1991; National Research Council, 1989; Department of Health, 1991). Accordingly, it is conceivable that the best doses in the long term are higher than those officially recommended (Pauling, 1974; Hughes, 1981; Hemilä, 1986; Levine \& Morita, 1985; Ginter, 1989; Reynolds, 1994). The studies with British males discussed in the present paper suggest that there are dose-dependent effects of vitamin $\mathrm{C}$ intake on health outcomes even in the absence of scurvy, and therefore the 
absence of overt scurvy should not be used as the sole criterion in considering the adequacy of vitamin $\mathrm{C}$ intake for healthy people.

The author is grateful to Drs Jouni Jaakkola and Martti Vaara for their helpful suggestions to improve the manuscript. This work was supported by the Juho Vainio Foundation and the Academy of Finland.

\section{REFERENCES}

Allen, R. J. L., Brook, M. \& Broadbent, S. R. (1968). The variability of vitamin C in our diet. British Journal of Nutrition 22, 555-563.

Anderson, R., Hay, I., van Wyk, H., Oosthuizen, R. \& Theron, A. (1980). The effect of ascorbate on cellular humoral immunity in asthmatic children. South African Medical Journal 58, 974-977.

Anderson, T. W., Reid, D. B. \& Beaton, G. H. (1972). Vitamin C and the common cold: a double-blind trial. Canadian Medical Association Journal 107, 503-508.

Anderson, T. W., Reid, D. B. \& Beaton, G. H. (1973) Vitamin C and the common cold (correction). Canadian Medical Association Journal 108, 133.

Anderson, T. W., Suranyi, G. \& Beaton, G. H. (1974). The effect on winter illness of large doses of vitamin C. Canadian Medical Association Journal 111, 31-36.

Baird, I. M., Hughes, R. E., Wilson, H. K., Davies, J. E. W. \& Howard, A. N. (1979) The effects of ascorbic acid and flavonoids on the occurrence of symptoms normally associated with the common cold. American Journal of Clinical Nutrition 32, 1686-1690.

Bates, C. J., Rutishauser, I., Black, A. E., Paul, A. A., Mandal, A. R. \& Patnaik, B. K. (1979). Long-term vitamin status and dietary intake of healthy elderly subjects. British Journal of Nutrition 42, 43-56.

Bergsten, P., Amitai, G., Kehrl, J., Dhariwal, K. R., Klein, H. G. \& Levine, M. (1990). Millimolar concentrations of ascorbic acid in purified human mononuclear leukocytes. Journal of Biological Chemistry 265, $2584-2587$.

Black, A. E., Billewicz, W. Z. \& Thomson, A. M. (1976). The diets of preschool children in Newcastle upon Tyne, 1968-71. British Journal of Nutrition 35, 105-113.

Block, G. \& Sorenson, A. (1987). Vitamin C intake and dietary sources by demographic characteristics. Nutrition and Cancer 10, 53-65.

Bolton-Smith, C., Woodward, M., Brown, C. A. \& Tunstall-Pedoe, H. (1993). Nutrient intake by duration of exsmoking in the Scottish Heart Health Study. British Journal of Nutrition 69, 315-332.

Bourne, G. H. (1949). Vitamin C and immunity. British Journal of Nutrition 2, 341-347.

Briggs, M. (1984). Vitamin C and infectious disease: a review of the literature and the results of a randomized, double-blind, prospective study over 8 years. In Recent Vitamin Research pp. 39-82 [M. H. Briggs, editor]. Boca Raton: CRC Press.

Burr, M. L., Elwood, P. C., Hole, D. J., Hurley, R. J. \& Hughes, R. E. (1974). Plasma and leucocyte ascorbic acid levels in the elderly. American Journal of Clinical Nutrition 27, 144-151.

Carson, M., Cox, H., Corbett, M. \& Pollitt, N. (1975). Vitamin C and the common cold. Journal of the Society of Occupational Medicine 25, 99-102.

Charleston, S. S. \& Clegg, K. M. (1972). Ascorbic acid and the common cold. Lancet i, 1401-1402.

Clegg, K. M. (1974). Studies associated with ascorbic acid. Acta Vitaminologica Enzymologica 28, 101-102.

Clegg, K. M. \& Macdonald, J. M. (1975). L-Ascorbic acid and D-isoascorbic acid in a common cold survey. American Journal of Clinical Nutrition 28, 973-976.

Crombie, I. K., Todman, J., McNeill, G., Florey, C. V., Menzies, I. \& Kennedy, R. A. (1990). Effect of vitamin and mineral supplementation on verbal and non-verbal reasoning of schoolchildren. Lancet 335, $744-747$.

Dahl, H. \& Degre, M. (1976). The effect of ascorbic acid on production of human interferon and antiviral activity in vitro. Acta Pathologica Microbiologica Scandinavica 84B, 280-284.

Darke, S. J., Disselduff, M. M. \& Try, G. P. (1980). Frequency distributions of mean daily intakes of food energy and selected nutrients obtained during nutrition surveys of different groups of people in Great Britain between 1968 and 1971. British Journal of Nutrition 44, 243-252.

Department of Health (1991). Dietary Reference Values for Food Energy and Nutrients for the United Kingdom. Report on Health and Social Subjects no. 41. London: H. M. Stationery Office.

Elwood, P. C., Lee, H. P., Leger, A. S., Baird, I. M. \& Howard, A. N. (1976). A randomized controlled trial of vitamin $\mathrm{C}$ in the prevention and amelioration of the common cold. British Journal of Preventive and Social Medicine 30, 193-196.

Evans, R. M., Currie, L. \& Campbell, A. (1982). The distribution of ascorbic acid between various cellular components of blood, in normal individuals, and its relation to the plasma concentration. British Journal of Nutrition 47, 473-482. 
Garry, P. J., Goodwin, J. S., Hunt, W. C. \& Gilbert, B. A. (1982). Nutritional status in a healthy elderly population: vitamin C. American Journal of Clinical Nutrition 36, 332-339.

Geber, W. F., Lefkowitz, S. S. \& Hung, C. Y. (1975). Effect of ascorbic acid, sodium salicylate, and caffeine on the serum interferon level in response to viral infection. Pharmacology 13, 228-233.

Ginter, E. (1989). Ascorbic acid in cholesterol metabolism and in detoxification of xenobiotic substances: problem of optimum vitamin $\mathrm{C}$ intake. Nutrition $5,369-374$.

Glazebrook, A. J. \& Thomson, S. (1942). The administration of vitamin C in a large institution and its effect on general health and resistance to infection. Journal of Hygiene 42, 1-19.

Hemilä, H. (1984). Nutritional need versus optimal intake. Medical Hypotheses 14, 135-139.

Hemilä, H. (1986). A re-evaluation of nutritional goals - not just deficiency counts. Medical Hypotheses 20, 1727.

Hemilä, H. (1991). Is there a biochemical basis for 'nutrient need'? Trends in Food Science and Technology 2 , 73.

Hemilä, H. (1992). Vitamin C and the common cold. British Journal of Nutrition 67, 3-16.

Hemilä, H. (1994). Does vitamin C alleviate the symptoms of the common cold? - A review of current evidence. Scandinavian Journal of Infectious Diseases 26, 1-6.

Hemilä, H. (1996a). Vitamin C, the placebo effect, and the common cold. A case study of how preconceptions influence the analysis of results. Journal of Clinical Epidemiology 49, 1079-1084.

Hemilä, H. (1996b). Vitamin C and common cold incidence: a review of studies with subjects under heavy physical stress. International Journal of Sports Medicine 17, 379-383.

Hemilä, H. \& Herman, Z. S. (1995). Vitamin C and the common cold: a retrospective analysis of Chalmers' review. Journal of the Americal College of Nutrition 14, 116-123.

Hess, A. F. (1932). Diet, nutrition and infection. New England Journal of Medicine 207, 637-648.

Hodges, R. E., Hood, J., Canhan, J. E., Sauberlich, H. E. \& Baker, E. M. (1971). Clinical manifestations of ascorbic acid deficiency in man. American Journal of Clinical Nutrition 24, 432-443.

Höjer, J. A. (1924). Studies in scurvy. Scurvy and infection. Acta Paediatrica 3 Suppl., 115-122.

Hughes, R. E. (1981). Recommended daily amounts and biochemical roles. In Vitamin C, pp. 75-86 [J. N. Counsell and D. H. Hornig, editors]. London: Applied Science Publishers.

Itoh, R., Yamada, K., Oka, J., Echizen, H. \& Murakami, K. (1989). Sex as a factor in levels of serum ascorbic acid in a healthy elderly population. International Journal for Vitamin and Nutrition Research 59, 365-372.

Karlowski, T. R., Chalmers, T. C., Frenkel, L. D., Kapikian, A. Z., Lewis, T. L. \& Lynch, J.M. (1975). Ascorbic acid for the common cold. A prophylactic and therapeutic trial. Journal of the American Medical Association 231, 1038-1042.

Kennes, B., Dumont, I., Brohee, D., Hubert, C. \& Neve, P. (1983). Effect of vitamin C supplements on cellmediated immunity in old people. Gerontology 29, 305-310.

Kleijnen, J., Riet, G. \& Knipschild, P. G. (1989). Vitamin C and the common cold; a review of the megadose literature (in Dutch). Nederlands Tijdschrift voor Geneeskunde 133, 1532-1535.

Levine, M. \& Morita, K. (1985). Ascorbic acid in endocrine systems. Vitamins and Hormones $42,1-64$.

Lonergan, M. E., Milne, J. S., Maule, M. M. \& Williamson, J. (1975). A dietary survey of older people in Edinburgh. British Journal of Nutrition 34, 517-527.

Ludvigsson, J., Hansson, L. O. \& Tibbling, G. (1977). Vitamin C as a preventive medicine against common colds in children. Scandinavian Journal of Infectious Diseases 9, 91-98.

Manzella, J. P. \& Roberts, N. J. (1979). Human macrophage and lymphocyte responses to mitogen stimulation after exposure to influenza virus, ascorbic acid, and hyperthermia, Journal of Immunology 123, $1940-1944$.

Milne, J. S., Lonergan, M. E., Williamson, J., Moore, F. M. L., McMaster, R. \& Percy, N. (1971). Leucocyte ascorbic acid levels and vitamin C intake in older people. British Medical Journal 4, 383-386.

National Research Council (1989). Recommended Dietary Allowances, 10th ed. Washington, DC: National Academy Press.

Oh, C. \& Nakano, K. (1988). Reversal by ascorbic acid of suppression by endogenous histamine of rat lymphocyte blastogenesis. Journal of Nutrition 118, $639-644$.

Oreopoulos, D. G., Lindeman, R. D., VanderJagt, D. J., Tzamaloukas, A. H., Bhagavan, H. N. \& Garry, P. J. (1993). Renal excretion of ascorbic acid: effect of age and sex. Journal of the American College of Nutrition $12,537-542$.

Pauling, L. (1970). Vitamin C and the Common Cold (reprinted in 1976 as Vitamin C, the Common Cold, and the $F l u$ ). San Francisco: Freeman.

Pauling, L. (1971). The significance of the evidence about ascorbic acid and the common cold. Proceedings of the National Academy of Sciences USA 68, 2678-2681.

Pauling, L. (1974). Are recommended daily allowances for vitamin C adequate? Proceedings of the National Academy of Sciences USA 71, 4442-4446.

Perla, D. \& Marmorston, J. (1937a). Role of vitamin C in resistance. I. Archives of Pathology 23, $543-575$.

Perla, D. \& Marmorston, J. (1937b). Role of vitamin C in resistance. II. Archives of Pathology 23, 683-712.

Pitt, H. A. \& Costrini, A. M. (1979). Vitamin C prophylaxis in marine recruits. Journal of the American Medical Association 241, 908-911. 
Reynolds, R. D. (1994). Vitamin supplements: current controversies. Journal of the American College of Nutrition 13, 118-126.

Riemersma, R. A., Oliver, M., Elton, R. A., Alfthan, G., Vartiainen, E., Salo, M., Rubba, P., Mancini, M., Georgi, H., Vuilleumier, J. P. \& Gey, K. F. (1990). Plasma antioxidants and coronary heart disease: vitamins $\mathrm{C}$ and $\mathrm{E}$, and selenium. European Journal of Clinical Nutrition 44, 143-150.

Robertson, E. C. (1934). The vitamins and resistance to infection: vitamin C. Medicine 13, $190-206$.

Rothman, K. J. (1986). Modern Epidemiology. Boston: Little, Brown and Company.

Schwerdt, P. R. \& Schwerdt, C. E. (1975). Effect of ascorbic acid on rhinovirus replication in WI-38 cells. Proceedings of the Society for Experimental Biology and Medicine 148, 1237-1243.

Siegel, B. V. (1974). Enhanced interferon response to murine leukemia virus by ascorbic acid. Infection and Immunity 10, $409-410$.

Siegel, B. V. (1975). Enhancement of interferon production by poly(rl) poly(rC) in mouse cell cultures by ascorbic acid. Nature 254, 531-532.

Smit, M. J. \& Anderson, R. (1990). Inhibition of mitogen-activated proliferation of human lymphocytes by hypochlorous acid in vitro: protection and reversal by ascorbate and cysteine. Agents and Actions 30, 338343.

Smithells, R. W., Ankers, C., Carver, M. E., Lennon, D., Schorah, C. J. \& Sheppard, S. (1977). Maternal nutrition in early pregnancy. British Journal of Nutrition 38, 497-506.

Trichopoulou, A. \& Vassilakou, T. (1990). Recommended dietary intakes in the European community member states. European Journal of Clinical Nutrition 44 Suppl. 2, 51-126.

Tyrrell, D. A. J., Craig, J. W., Meade, T. W. \& White, T. (1977). A trial of ascorbic acid in the treatment of the common cold. British Journal of Preventive and Social Medicine 31, 189-191.

Walker, G. H., Bynoe, M. L. \& Tyrrell, D. A. J. (1967). Trial of ascorbic acid in prevention of colds. British Medical Journal 1, 603-606.

Washko, P. W., Wang, Y. \& Levine, M. (1993). Ascorbic acid recycling in human neutrophils. Journal of Biological Chemistry 268, 15531-15535.

Yonemoto, R. H. (1979). Vitamin C and immune responses in normal controls and cancer patients. International Journal for Vitamin and Nutrition Research Suppl. 19, 143-154. 